\section{Surveillance of Bioterrorism Agents: Considerations for EM Laboratories}

\author{
Sara E. Miller \\ Duke University Medical Center \\ mille012@mc.duke.edu
}

Biowarfare was first documented in the eighteenth century during the French and Indian War when the British distributed smallpox-contaminated blankets to the American Indians. Smallpox is considered a likely agent even today because the USSR was known to have produced and stockpiled large amounts of the virus even after signing the 1972 treaty prohibiting such production. Because of the large number of workers involved and the poor economy, the security of these stockpiles is unclear $[1$, txtwriter.com/Backgrounders/Bioterrorism/bioterror 4 ,html]. Since the terrorist attacks in the United States in 2001, world attention has been drawn to terrorism and potential release of dangerous biological organisms. Considerable efforts are being made to establish methods for rapidly recognizing these agents. Numerous electron microscopy (EM) laboratories have been approached to join rapid response teams for the detection of viral agents. However, several issues should be carefully considered before an EM laboratory agrees to participate in surveillance,

EM laboratories frequently are not set up to handle biohazardous specimens, and if they are, they most likely are not equipped with a biosafety level 3 (BSL-3) containment facility. Specific guidelines have been established by the Centers for Disease Control and Prevention for processing potential poxvirus specimens for EM (www.bt.cdc.gov/labissues/index.asp). Other important considerations include the immune status of
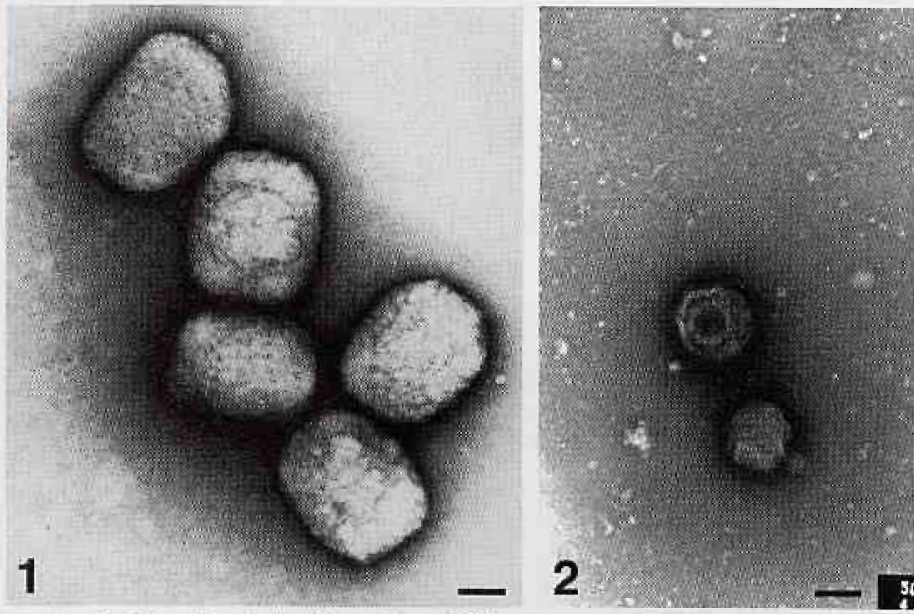

1. Negative stain of poxvirus, Virions are $\sim 115-250 \times 200-350-\mathrm{nm}$ oval or brick-shaped particles, depending on the genus. The dumbbellshaped core (see $3 d$ ) is not seen in these preparations in the absence of the envelope, and the stain rarely penetrates the whole particle to elucidate the core. The surface of the virions is rough and may appear as though the particle is wrapped with rope, also depending on the genus. The bar represents $100 \mathrm{~nm}$.

2. Negative stain of herpesvirus. Complete virions are $-150-200$ $n m$ enveloped particles. Short projections on the envelope surface are rarely visible in clinical material. The nucleocapsid inside the envelope is icosahedral and can be seen if the stain has penetrated the envelope membrane (center particle). Nucleocapsids ( $-100 \mathrm{~nm}$ ) may be found without envelopes and can be distinguished by size from adenoviruses. ( $\sim 80 \mathrm{~nm}$ ). Complete virions not penetrated by negative stain (lower right) are not clearly identifiable as viruses because cell membrane debris would appear similar. The bar represents $100 \mathrm{~nm}$.
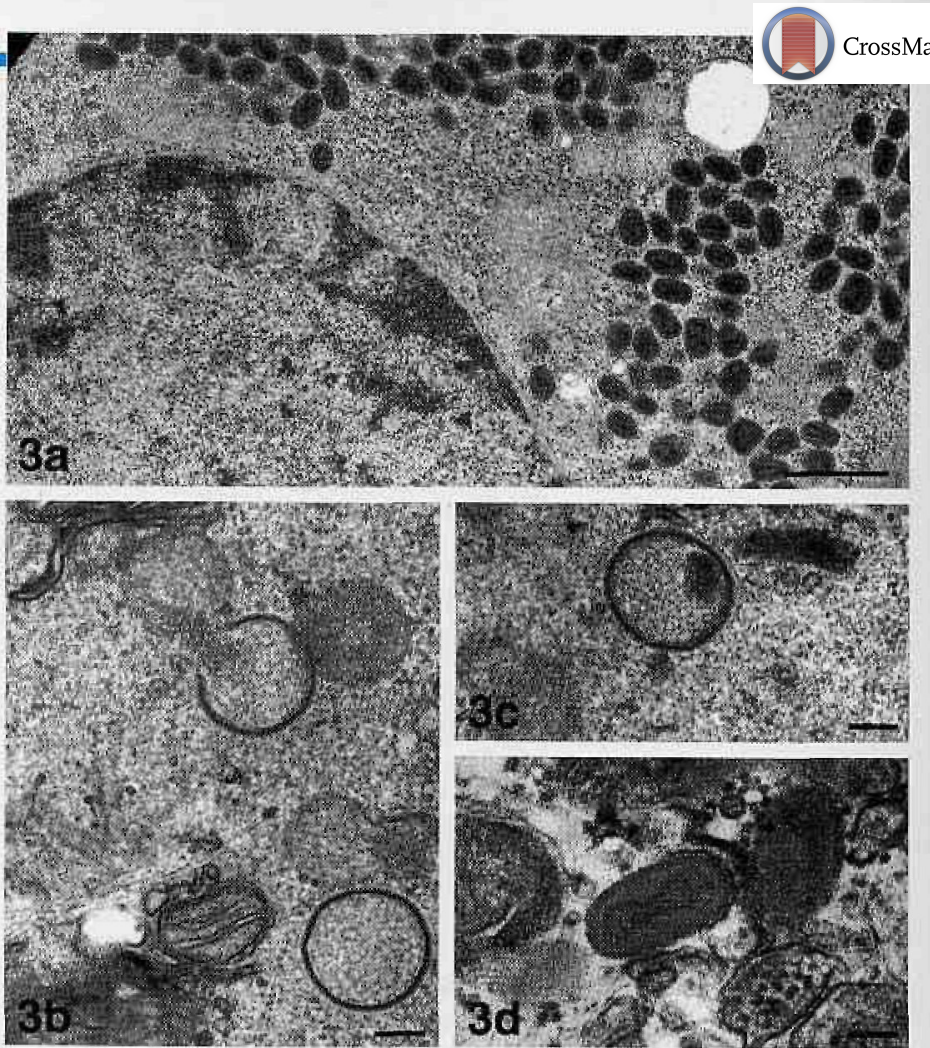

3. Thin sections of poxvirus-infected cells, a. Low magnification showing virus replication in the cytoplasm (dark oval bodies). Most DNA viruses replicate in the nucleus, but poxviruses are an exception and are never found there. The bar represents $1 \mu \mathrm{m}$. b. Immature particles. $c$. Immature particle with condensing nucleic acid core. d. Mature particle showing the dumbbell-shaped core. The bars in b-c represent $100 \mathrm{~nm}$.
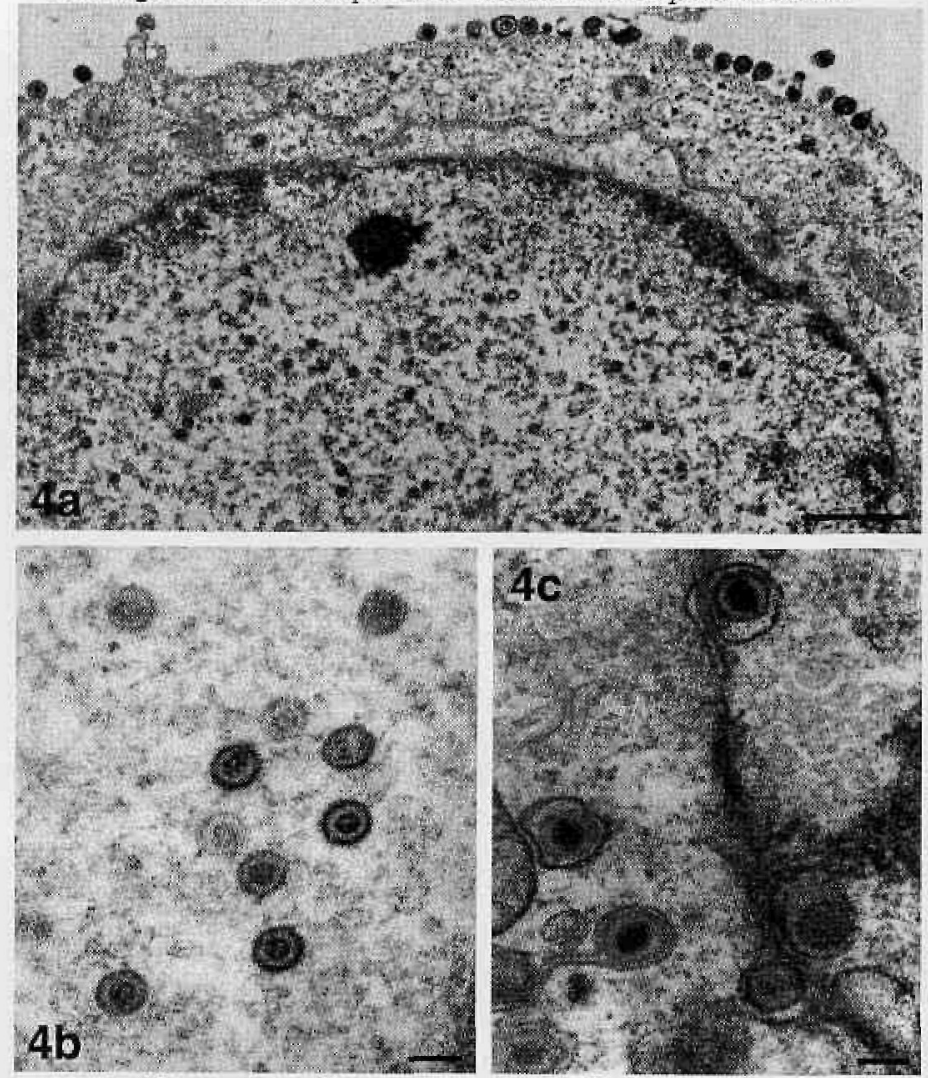

4. Thin sections of herpesvirus-infected cells. a. Low magnification showing nucleocapsids in the nucleus and complete virions budding from the cytoplasmic membrane. This DNA virus produces spherical nucleocapsids in the nucleus; the envelope may be obtained by nucleocapsid budding through the nuclear membrane, internal cytoplasmic membranes, or plasma membrane. The bar represents $1 \mathrm{\mu m}$. b. 100-nm nucleocapsids in the nucleus. c. Complete enveloped virus particles in the cytoplasm on the left and nucleocapsids in the nucleus on the right budding through the nuclear membrane out into the cytoplasm on the left. The bars in b and $c$ represent $100 \mathrm{~nm}$. 


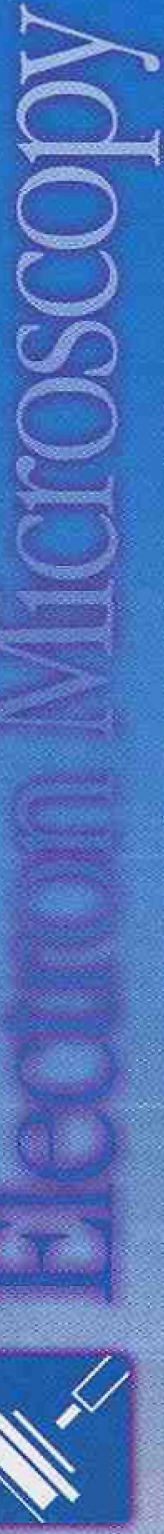

\section{for Specimen Preparation.}

lon Bean Sputter

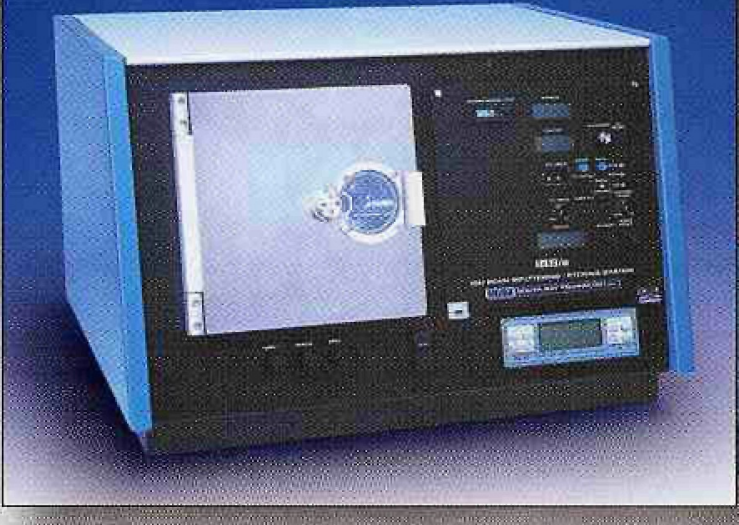

Deposition and Etching System

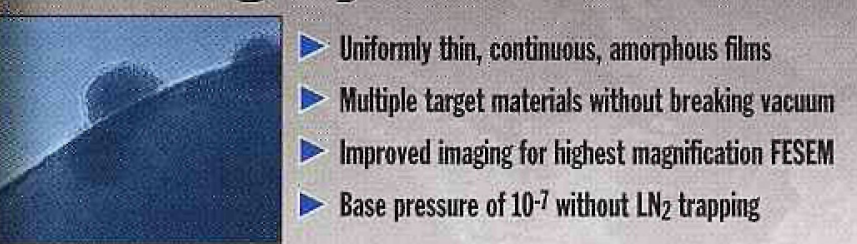

\section{Plasma Cleaner}

Removes hydrocarbons without damaging specimen 4 Intuitive front panel controls $\varangle$

Ideal for multi-user environments 4 Large chamber accommodates samples $\varangle$ up to $3^{\prime \prime}$ tall and $6^{\prime \prime}$ diameter
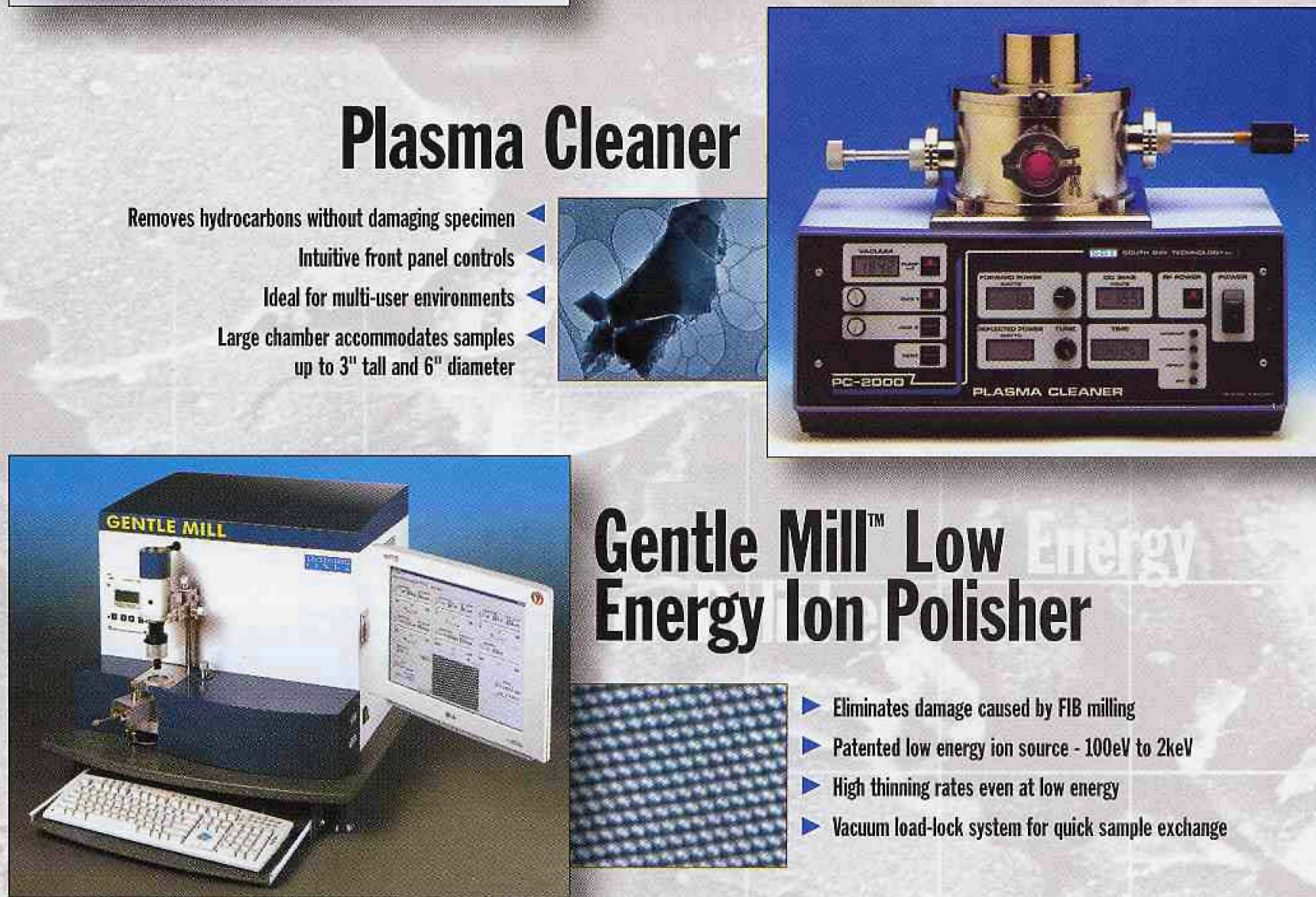

- Patented low energy ion source - $100 \mathrm{eV}$ to $2 \mathrm{keV}$

- High thinning rates even at low energy

V Vacuum load-lock system for quick sample exchange

www.southbaytech.com

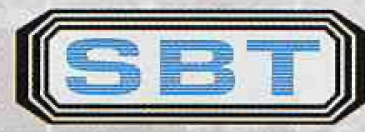

\section{SOUTH BAY TECHNDLOEY, INE.}

1120 Via Callejon | San Clemente, CA 92673 | U.S.A. | 949-492-2600 | Fax: 949-492-1499

Toll Free: 800-728-2233 | email: info@southbaytech.com | www.southbaytech.com 


\section{Algorithm for EM Laboratory Participation in Smallpox Surveillance Plan NOW. Decide whether you can or will assist in diagnosis BEFORE the situation arises}

Yes (I wish to consider having specimens sent to me.)

Requirements:

1. Diagnostic capability

2. Biohazard containment

3. Vaccination

1. Diagnostic Capability

Yes

Know virus morphology (a.), look-alikes/artifacts (b.)

Have experience with negative staining

Have access to hydrophilic film-coated grids
No (I have no desire to handle potential poxvirus cases.) Refer the inquiry to your state public health lab or LRM (Laboratory Response Network)

a. Virus morphology

Poxvirus infections are most likely to be confused with varicella-zoster virus (VSV) infections.

Poxviruses are $\sim 200 \times 300-\mathrm{nm}$, brick-shaped virions. In sections, they are found in the cytoplasm, not usually budding.

Herpesviruses are $\sim 150-200$-nm enveloped virions with spherical $\sim 100$-nm nucleocapsids. In sections, nucleocapsids are seen in the nucleus; whole virions are found budding from cell membranes.

b. Virus look-alikes/artifacts

Poxviruses: In negative stains, lipid, melanosomes, and rectangular crystals may resemble viruses. In thin sections confusing structures include lipid, melanosomes, pigment, mitochondria, microbodies, secretory granules, and crystalline inclusions.

Herpesviruses: In negative stains membrane debris and adenoviruses may resemble herpesviruses. In thin sections cell components such as nuclear bodies, nuclear pores, secretory granules, coated vesicles, and membranebound lipid may look like viruses.

\section{Biohazard containment}

Yes

Requires BSL-2 cabinet and BSL-3 precautions

Arrange courier service

(special packaging and transport)

\section{Vaccination}

Yes

Have been vaccinated within last 5 years

No contraindications (c.) to post-exposure vaccination

c. Contraindications (See www.cdc.gov/mmwr, click on Smallpox Vaccination and Adverse Reactions)

Skin lesions

Impaired immune system

Close contact with others who have contraindications to vaccination
No

Accept only fixed specimens

No
Accept only fixed specimens the microscopist(s), collection and transfer of the specimen to the EM lab, whether to permit only fixed material into the laboratory, and whether the EM lab staff has experience preparing viral specimens and identifying viruses [2-4]. Laboratory directors should discuss their capabilities and the desirability of becoming involved in the response to a potential terrorist event before one occurs, not only with EM staff, but also upper administrators.

Smallpox virus is the viral agent of most concern because of its potential access by rogue nations and because of the ease of dissemination. The agent with which smallpox is most likely to be confused is herpes varicella-zoster virus, the virus that causes chickenpox and shingles; the CDC has provided a rash illness protocol (www.bt.cdc.gov/agent/smallpox/diagnosis/evalposter.asp).

EM is the fastest diagnostic modality to differentiate these agents. An EM laboratory should become involved in surveil- lance of poxviruses only if its staff has experience in detecting viral agents. False positive results on a blister fluid, e.g., describing a melanosome as a poxvirus, or false negative results, e.g., failing to detect a poxvirus, would result in considerable confusion or potential disastrous delay of identification. Personnel not experienced in virology but wishing to contribute to the surveillance effort can certainly train in one of the EM virology laboratories.

Individuals who have not been recently vaccinated against smallpox or who could not be immediately immunized if exposed should not collect or handle potential smallpox specimens. An alternative would be to instruct primary health care workers in the collection of specimens and have the specimen inactivated by fixation in glutaraldehyde before transport. Transport of specimens from the point of collection to the diagnostic laboratory should follow accepted procedures. Each health care institution has guidelines governing transport of clinical specimens, and EM labs not 
accustomed to handling potentially infectious material should be well aware of the rules before bringing in a dangerous agent.

Electon microscopy laboratory directors should carefully weigh the pros and cons of becoming involved in virus surveillance before events occur so that split-second decisions are not incorrectly made that would endanger health or produce an inaccurate diagnosis. See the algorithm above.

Figure Comments:

The disease with which smallpox is most likely to be confused in the early stages is chickenpox or its recrudescence as shingles (caused by varicella-zoster virus, a herpesvirus). Electron microscopy of negatively stained lesion scrapings can easily distinguish poxviruses from herpesvirus in a very short time ( 10-15 $\mathrm{min}$ ). Routine thin sections of tissue take longer to prepare, usually overnight, but can be accomplished in 2-3 hours in rush situations. These figures show identifying virus characteristics.

Notes:

- Micrographs are reprinted from reference 2 .

- This article is a preprint of a paper to be given at the Microscopy \& Microanalysis-2004 meeting in Savannah.

\section{References:}

[1] J.B Tucker, The Once and Future Threat of Smallpox. Atlantic Monthly Press, New York, 2001.

[2] S.E. Miller, Ultrastruct, Pathol. 27 (2003) 133.

[3] S.E. Miller, in E.H. Lennette, D.A. Lennette, E.T. Lennette (eds.) Laboratory Diagnosis of Viral Infections, ed. 3. New York, Dekker, 1995, pp. 37-78.

[4] H.R. Gelderblom, P. R. Hazelton, Emerg. Infect, Dis. 5 (2000) 842.

\section{American Superconductor}

REVOLUTIONIZING THE WAY THE WORLD USES ELECTRICITY"

\section{Electron Microscopist}

American Superconductor Corporation seeks a full-time, hands-on Microscopist. The individual will be responsible for the overall dayto-day operation of two Scanning Electron Microscopes, along with specimen preparation, coordination of materials supplies, record keeping, and presenting results of studies to customers. Minimum requirements: BS degree in a related field or AAS in SEM technology with $3+$ years experience with SEM/EDS including materials characterization, and data analysis. Flexible working hours are required. Microstructure and energy dispersive spectrometry interpretation are required.

Submit resume by e-mail to: resumes@amsuper.com

or by mail or FAX to:

American Superconductor, Attention: Human Resources, 2 Technology Drive, Westborough, MA 01581, Fax: 508-366-1057
$3 \mathrm{~nm}$ !

Improved SEM Performance!

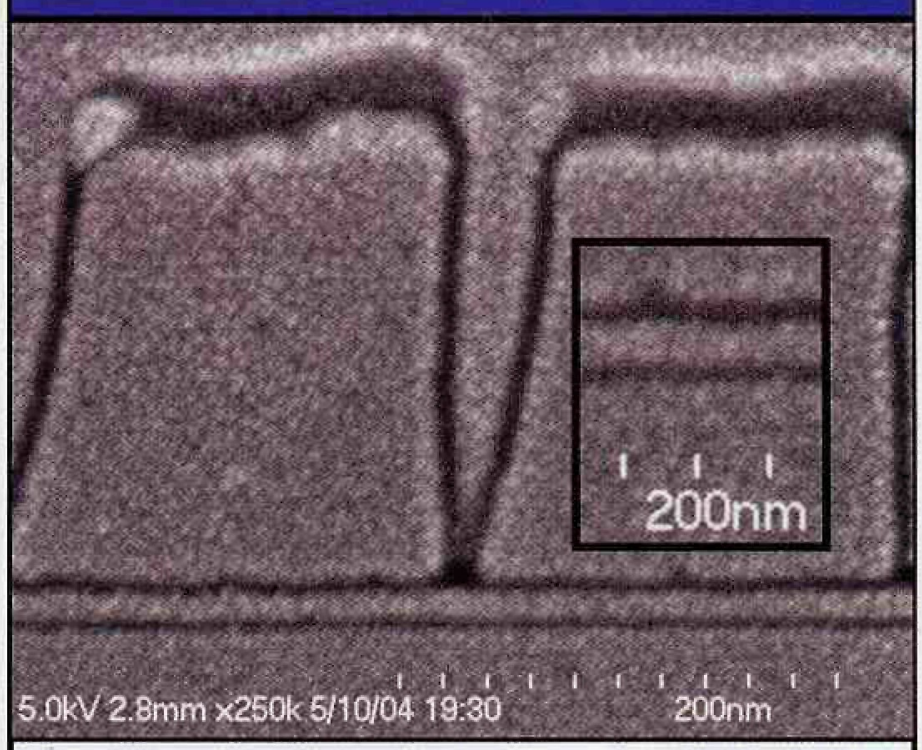

Sputtered Pt on IC wafer cross section after Evactron $\circledast$ cleaning of Hitachi S- 4700 chamber. $3 \mathbf{~ n m ~ P t ~ g r a i n s ~ a r e ~ v i s i b l e ! ~}$

\section{Evactron $®$}

\section{Anti-Contaminator}

The Evactron $\oplus$ Anti-Contaminator is well known for its ability to stop black squares and other scan deposits caused by oils and organics. The Evactron A-C is now shown to improve the performance of dry pumped $\mathrm{Fe}$ SEMs with increased contrast and resolution by removing residual hydrocarbons. With less than 5 minutes per week of Evactron cleaning, you can get the best possible pictures from your SEM or FIB.

The Evactron A-C uses air in a remote RF Plasma process to oxidize hydrocarbons out of the vacuum chamber. Five minutes of Evactron cleaning a week can keep your SEM at maximum performance.

\section{Ask us for details!}

\section{XEI SCIENTIFIC}

1735 East Bayshore Rd, Suite 29A, Redwood City, CA 94063 (650) 369-0133, FAX (650) 363-1659 email: sales@Evactron.com WwW.EVACTRON.COM 